\title{
The influence of customer orientation on emotional labour and work outcomes: a study in the tourism industry
}

\author{
Gabriela S. Marques ${ }^{1 *}$, Anabela Correia ${ }^{2}$ and Carlos M. Costa ${ }^{3}$
}

Received: 29/12/2017 Accepted: 08/05/2018

\footnotetext{
1 Universidade Europeia, Laureate International Universities, Quinta do Bom Nome, Estrada da Correia 1500 210 Lisboa, Portugal, gabriela.marques@universidadeeuropeia.pt

2 Polytechnic Institute of Setúbal \& GOVCOPP, Campus do IPS, Estefanilha 2914-503 Setúbal, Portugal, anabela.correia@esce.ips.pt

3 University of Aveiro, Campus Universitário de Santiago 3810-193 Aveiro, Portugal, ccosta@ua.pt

* Corresponding author
}

\begin{abstract}
How service employees express their emotions with customers is an important part of service quality. However, the emotional expressiveness of contact employees can be affected by the importance they give to customers and can have consequences on their work attitudes and wellbeing. This study aims to explore the influence of customer orientation in emotional labour strategies and analyses the impact of emotional labour strategies on four outcomes: burnout, affective delivery, job satisfaction and affective commitment. The sample consisted of 283 contact employees from hotels and travel agencies. The results show that organisational customer orientation promotes the expression of genuine emotions and that individual customer orientation fosters both deep acting and expression of genuine emotions. The study reveals that while surface acting promotes both emotional exhaustion and depersonalisation, deep acting promotes affective commitment. Finally, it is shown that the expression of genuine emotions fosters personal accomplishment, affective delivery, job satisfaction and affective commitment. Findings provide insight for organisations and managers about the importance of customer orientation in management of emotions in customer service and how can have positive implications on employees and on the quality of service.
\end{abstract}

(C) 2018 Varna University of Management. All rights reserved

Keywords: Customer orientation, emotional labour, contact employees

Citation: Marques, G.S., A. Correia, C.M. Costa (2018). The influence of customer orientation on emotional labour and work outcomes: a study in the tourism industry. European Journal of Tourism Research 20, pp. 59-77

\section{Introduction}

Due to the economic and social expansion of worldwide tourism, organisations operating in this industry need to improve customer orientation effectiveness where contact employees play an important role. Contact 
The influence of customer orientation on emotional labour and work outcomes: a study in the tourism industry.

employees, core representatives of the organisation, must respond both to customer expectations and management requirements (Chung and Schneider, 2002; Grönroos, 2001; Tax et al., 2013). These employees are expected to show positive emotions when interacting with customers, as a way of generating and maintaining positive feelings on the part of the customers (Barger and Grandey, 2006; Kim et al., 2017). Emotional display in customer contact employees, can change the emotional state of customers, and its strength is influenced by employees' authenticity (Grandey et al., 2005; Pugh, 2001; Tsai and Huang, 2002).

The presentation of appropriate emotions in each type of interaction incorporates the concept of emotional labour (Ashforth and Humphrey, 1993; Hochschild, 1983). The display of appropriate emotions may require the aligning of emotions, i.e. masking them (surface acting), manipulating them cognitively (deep acting), or the expression of genuine emotions (expression of genuine emotions). These are described in the literature as emotional labour strategies (Diefendorff et al., 2005; Grandey, 2000). Literature has addressed factors influencing the choice of emotional labour strategies in particular the situational ones, such as rules of emotional presentation and the nature of the interactions, and the individual ones, such as personality and affectivity (e.g., Brotheridge and Grandey, 2002; Brotheridge and Lee, 2002; Diefendorff et al., 2011; Diefendorff et al., 2005; Diefendorff et al., 2016; Gosserand and Diefendorff, 2005; Grandey, 2003; Hur et al., 2015; Kim et al., 2017; Morris and Feldman, 1997; Mróz and Kaleta, 2016).

There have been few studies of the effect of customer orientation, at the organisational and individual levels, on emotional labour strategies, particularly in the tourism business. The organisational customer orientation is an organisational philosophy, that is based on an understanding of customer expectations and competitive trends, that contributes to the competitive differentiation of the organisations involved (Deshpandé et al., 1993). In customer service situations, contact employees are a key resource in ensuring the effectiveness of a customer-oriented organisation (Zablah et al., 2012). The contact employee's performance quality is one of the main effects of customeroriented behaviors (Brady and Cronin, 2001; Lee et al., 2016; Lings and Greenley, 2010; Yoo and Arnold, 2014; Zablah et al., 2012; Zeithaml et al., 2017). As performance quality derives from the quality of emotional displays (Pugh, 2001; Tsai and Huang, 2002), it is potentially relevant to relate individual customer orientation to emotional labour strategies.

However, the emotional experience underlying the emotional labour strategies may have repercussions for the expression of positive emotions (affective delivery), in physical and psychological well-being (burnout) and attitudes to the work and to the organisation as in the case of job satisfaction and affective commitment (Brotheridge and Grandey, 2002; Brotheridge and Lee, 2002; Grandey, 2003, 2015; Grandey and Gabriel, 2015; Groth et al., 2009; Hülsheger and Schewe, 2011; Lee and Woo, 2017; Kammeyer-Mueller et al., 2013; Karatepe and Choubtarash, 2014; Wang et al., 2016).

The aim of this study was to examine the influence of customer orientation (organisational and individual) on emotional labour strategies and to test the effects of emotional labour strategies on four work outcomes: burnout, affective delivery, job satisfaction and affective commitment.

\section{Literature review}

\section{Emotional labour strategies}

Emotional labour may be described as the presentation of appropriate emotions by employees in each type of interaction, presupposing the following: (a) there is a faceto-face or distance interaction; (b) the employee produces an emotional state in another person; and (c) the organisation controls employee activity through rules, supervision and training (Ashforth and Humphrey, 1993; Hochschild, 1983).

Emotional labour is frequently described in the literature through two enacting strategies: surface acting and deep acting (Grandey, 2000). When employees use surface acting strategies, they express the required emotions 
without feeling them. They mask their own feelings and reproduce the desired emotions. When employees use deep acting strategies, they express the required emotions but also feel them, by making the effort to cognitively modify their own thoughts and feelings. Although many studies have highlighted the strategies of deep and surface acting, many researchers see them as compensatory strategies that help employees to express emotions that they would not normally feel by appealing to the need to include analysis of the expression of genuine emotions (Ashforth and Humphrey, 1993; Brotheridge and Grandey, 2002; Diefendorff et al., 2005). The expression of genuine emotions occurs when employees spontaneously experience and present the emotions organisational required. In such cases, no effort needs to be made to regulate emotions (Diefendorff and Gosserand, 2003; Diefendorff et al., 2005). This genuine presentation of target emotions comprises emotional labour when employees make a conscious effort to ensure that their emotional displays coincide with organisational expectations. In fact, the work of Diefendorff et al. (2005) showed that the expression of genuine emotions is a distinct construct from both deep and surface acting and that it plays a key role in employee emotional presentation when interacting with customers.

\section{Organisational customer orientation and} emotional labour strategies

The present study takes the same view of Deshpandé et al. (1993), who conceptualized organisational customer orientation (OCO) as an organisational culture anchored in a set of beliefs, standards and norms that put the customer first. The prioritization of the customer is underpinned by a continual process of socialization that makes it possible for the employees to internalize and share the organisation's values and norms (Kohli and Jaworski, 1990; Narver and Slater, 1990). This collective sharing may influence the attitudes and behaviours of all who are engaged in customer service (Carr and Lopez, 2007; Mengüc, 1996; Pelham, 2009). A customeroriented organisational culture has rules of conduct that largely address the display of specific emotions in customer contact situations (Pelham, 2009). The emotional presentation rules list the emotions to be displayed in contacts with customers (Rafaeli and Sutton, 1987, 1989). According to Ashforth and Humphrey (1993), compliance with emotional presentation rules underlies the employee's identification with the role and can facilitate the alignment of the emotional experience with the effective expression of the emotions.

Thus, it is expected that a customer-oriented culture enhances employee adjustment to organisational expectations. Moreover, this will help ensure that customer contacts are marked by the presentation of appropriate and authentic emotions, delivered through the mechanisms of deep acting and the expression of genuine emotions. On the other hand, employees will not feel a need to mask their emotions. So, we propose the following hypotheses:

\section{H1a. Organisational customer orientation will} be negatively related to surface acting.

H1b. Organisational customer orientation will be positively related to deep acting.

H1c. Organisational customer orientation will be positively related to genuine emotions.

\section{Individual customer orientation and emotional} labour strategies

During the customer service experience, it is the contact employees are the ones who implement the customer orientation (Donavan et al., 2004). One landmark publication on individual customer orientation (ICO) resulted from the study carried out by Saxe and Weitz (1982) that emphasized the shift from attitudes focused on immediate business outcomes to those designed to help customers make purchasing decisions and develop long-lasting relationships. Guided by the principle of "concern for others", the concept values the type of positive relationships with customers that lead to fulfilment of their needs and to their satisfaction. Other studies have determined ICO to be a superficial personality trait, arguing that the combination of basic personality traits with a specific context produces superficial traits that manifest themselves in the form of a predisposition to the display of those specific behaviours that are related to this same context (Brown et al., 2002; Donavan et al., 2004). 
The influence of customer orientation on emotional labour and work outcomes: a study in the tourism industry.

Notwithstanding the important contribution made by these studies to the literature on ICO, it must be said that the constructs developed are more self-assessment measures of the likelihood of meeting customers' needs and the extent to which they like to do this rather than measures of the behaviours to be displayed during the service provision. Given that the aim is to examine ICO as a precursor of emotional labour strategies, it is believed to be more appropriate to adopt the Saxe and Weitz (1982) concept. Although this also reflects a predisposition, it does assess behaviours designed to produce customer satisfaction.

The influence of ICO on the quality of employee-customer relations has been described in the literature, particularly as regards cooperative dialogue and a more trustworthy and authentic service (Brady and Cronin, 2001; Lee et al., 2016; Lings and Greenley, 2010). Also, Smith et al. (2012), in a study applied to restaurant employees, revealed that employees with high $\mathrm{CO}$ levels are more engaged with customer service by delivering meaningful interpersonal relationships through warmth, empathy and consideration. Active participation in meeting target objectives and adjustments to the demands of the job (Donavan et al., 2004; Mengüc, 1996; Zablah et al., 2012) indicate that customer-oriented employees try to produce emotional displays that conform to the organisation's presentation rules. According to Brotheridge and Grandey (2002), conscious interactions, based on positive emotional expressiveness, were positively related to the deep acting. This idea is reinforced by Rupp et al., (2008) which suggests that customeroriented employees, assuming the client's perspective, in a logic of deep acting, need less resorting to surface acting.

Moreover, the positive effect of ICO on the experiencing of positive emotions in the workplace (Franke and Park, 2006; Harris et al., 2005; Zablah et al., 2012) may facilitate the alignment of emotional experience with the effective emotional expression.

Thus, it is to be expected that, in customer service situations, customer-oriented employees will display the emotions required of them by the organisation in an authentic manner, through the mechanisms of deep acting and the expression of genuine emotions. On the other hand, it is expected that these employees will not feel a need to mask their emotions. Therefore, we propose that:

H2a. Individual customer orientation will be negatively related to surface acting.

H2b. Individual customer orientation will be positively related to deep acting.

H2c. Individual customer orientation will be positively related to expression of genuine emotions.

\section{Emotional labour strategies and burnout}

The effort expended in presenting the appropriate emotions and the requirement to repeatedly display emotions that need to be regulated can lead to burnout. Burnout may be defined as chronic emotional tension that involves emotional exhaustion, depersonalization and lack of personal accomplishment (Maslach, 1993). Emotional exhaustion refers to feelings of emotional overload and an inability to meet the interpersonal demands of the job due to constant pressures at work. Depersonalisation manifests itself as the development of negative and insensitive attitudes directed at those with whom the person interacts at work. It is a key factor in customer service, given the possibility of losing empathy with, or interest in, the customers (Grandey, 2000). Finally, the lack of personal accomplishment results from negative self-assessment feelings, such as failure, low self-esteem and a lowering of personal expectations, all of which can impact on the efficacy of customer service work (Grandey, 2000).

In the literature, these dimensions of burnout have been taken to be the consequences of emotional labour strategies. Firstly, because of the emotional tension caused by the emotional dissonance generated by the discrepancy between the emotions as felt and the emotions as desired (Middleton, 1989) and, secondly, because of the energy spent in making the effort to present appropriate emotions (Ashforth and Humphrey, 1993; Grandey, 2000). More specifically, prior studies have revealed the negative repercussions that surface acting has 
for individual well-being and its influence on burnout (Brotheridge and Grandey, 2002; Brotheridge and Lee, 2002; Grandey, 2003; Hülsheger and Schewe, 2011; Judge et al., 2009; Kammeyer-Mueller et al., 2013; Lee and Woo, 2017).

Deep acting has been linked to feelings of personal accomplishment and lower levels of negative emotions (Brotheridge and Grandey, 2002; Brotheridge and Lee, 2002; Grandey, 2003; Groth et al., 2009; Hülsheger and Schewe, 2011). The expression of genuine emotions, as well as deep acting, is reflected in the authenticity of the emotional display. However, and as regards the experiencing of the emotions, it is different from both deep and surface acting, since no effort is being made to regulate emotions. This has a positive impact on individual well-being (Ashforth and Humphrey, 1993; Grandey, 2000; Morris and Feldman, 1996).

Thus, it is to be expected that emotional labour strategies that imply some effort to regulate emotions (surface and deep acting) would increase both emotional exhaustion and depersonalization and that they would correlate negatively with personal accomplishment. It is likely that the expression of genuine emotions has a negative effect on both emotional exhaustion and depersonalization, whereas it increases personal accomplishment. Based on the above studies, we propose the following hypotheses:

H3a. Surface acting will be positively related to emotional exhaustion and depersonalization.

$H 3 b$. Surface acting will be negatively related to personal accomplishment.

H3c. Deep acting will be positively related to emotional exhaustion and depersonalization.

$H 3 d$. Deep acting will be negatively related to personal accomplishment.

H3e. Expression of genuine emotions will be negatively related to emotional exhaustion and depersonalization.

H3f. Expression of genuine emotions will be positively related to personal accomplishment.

\section{Emotional labour strategies and affective delivery}

Affective delivery of the service pertains to the degree to which customer's contacts are based on the expression of such positive emotions as pleasantness, enthusiasm and politeness (Bettencourt, Gwinner and Meuter, 2001; Gosserand and Diefendorff, 2005; Grandey, 2003).

In service organisations, a positive emotional performance can benefit the relationship with the customer, particularly the perception of the quality of the service and the willingness to return and to recommend (Barger and Grandey, 2006; Grandey, 2003; Grandey and Gabriel, 2015; Kim et al., 2017; Pugh, 2001; Rafaeli and Sutton, 1987, 1989; Schneider and Bowen, 1985; Tsai and Huang, 2002; Wang et al., 2016).

For Ashforth and Humphrey (1993), the key factor for effective affective service delivery is the perception of authenticity. Previous studies showed that, in contact situations, the interlocutors recognize the authenticity of smiles and react less well to expressions that are perceived to be false (Grandey et al., 2005; Ekman et al., 1988; Frank et al., 1993). Although they both involve putting the rules of emotional presentation into practice, surface and deep acting can be separated by the degree of authenticity of the emotional display (Grandey, 2000). For example, the study carried out by Grandey (2003) showed that affective delivery is positively related to deep acting and negatively related to surface acting. The author justifies these results based on the "power that deep acting has to convince the audience", which means it can work as a facilitator. However, a study by Gosserand and Diefendorff (2005) of the impact of emotional acting strategies (deep and surface acting) on affective delivery found no correlation with this dimension.

Although the empirical studies have been less than conclusive with regard to the relation between emotional labour strategies and affective delivery, they do suggest that strategies related to the authenticity of expression can contribute positively to interactions based on the expression of positive emotions. Thus, it is predictable that deep acting strategies and the expression of genuine 
The influence of customer orientation on emotional labour and work outcomes: a study in the tourism industry.

emotions will increase the affective delivery and that the masking of emotions will reduce it. Therefore, the following hypotheses are proposed:

H4a. Surface acting will be negatively related to affective delivery.

H4b. Deep acting will be positively related to affective delivery.

H4c. Expression of genuine emotions will be positively related to affective delivery.

Emotional labour strategies and global job satisfaction

Job satisfaction is "a pleasurable or positive emotional state resulting from an appraisal of one's job or job experiences" (Locke, 1976, p.1300). The importance of job satisfaction to employee performance in customer contact situations has been pointed out in the literature that emphasizes the need for organisations to promote employee satisfaction as a way to increase loyalty and productivity, contributing to service quality and customer satisfaction (Homburg and Hoyer, 2009; Rogers et al., 1994).

During customer contacts, the employment of emotional labour strategies involves experiencing and managing the emotions themselves that can result in either a positive or a negative work experience. Earlier studies have shown that the emotions felt during work experiences feed into job satisfaction (Fisher, 2000; Hülsheger and Schewe, 2011; Judge et al., 2009; Kammeyer-Mueller et al., 2013; Lee and Woo, 2017).

In terms of emotional experience, if the expectation of the display of positive emotions to the customers can generate these emotions and feelings of job satisfaction (Fisher, 2000), however, for Hochschild (1983), the work that requires the management of something as personal as the emotions proposed by the organisation must be inherently unsatisfying. The emotional dissonance, the loss of the feeling of authenticity and individual states of anguish triggered by surface acting are all possible causative factors in job dissatisfaction (Grandey, 2003; Hülsheger and Schewe, 2011; Judge et al., 2009; Kammeyer-Mueller et al., 2013; Lee and Woo, 2017; Morris and
Feldman, 1997; Pugh et al., 2011). This is not the case for deep acting, which has been positively correlated with the perception of authenticity itself and with job satisfaction (Brotheridge and Lee, 2002; Grandey, 2003; Groth et al., 2009). For example, the study carried out by Hülsheger and Schewe (2011) shows that deep acting result in employees feeling that they are doing their job better and feeling more satisfied about the work they are doing. If this is the case, the expression of genuine emotions will, by definition, have a similar, if not greater, effect, in terms of these same feelings.

In terms of emotional display, while surface acting may lead to perceptions of distorted service delivery and negative perceptions of service quality, deep acting may contribute to authentic and more effective service provision accompanied by positive perceptions of service quality (Grandey, 2003; Groth et al., 2009; Hülsheger and Schewe, 2011; KammeyerMueller et al., 2013). The alignment of one's own emotions with the desired emotions may lead to authentic emotional expression, with positive repercussions for job satisfaction (Sheldon et al., 1997).

It seems likely, therefore, that the employment of emotional labour strategies that strengthen both the sense of authenticity and the authenticity of the emotional display (deep acting and the expression of genuine emotions) engenders positive work experiences and contributes to boosting job satisfaction. Conversely, surface acting may undermine the sense of authenticity and the quality of the performance, with a negative knock-on effect on job satisfaction. Thus:

H5a. Surface acting will be negatively related to job satisfaction.

H5b. Deep acting will be positively related to job satisfaction.

H5c. Expression of genuine emotions will be positively related to job satisfaction.

Emotional labour strategies and affective commitment

Affective commitment is manifested through the employee's affective bond to the organisation, the extent to which they identify with the target 
objectives, the hard work that they put in for the benefit of the organisation and the value that they attach to being members of it (Mowday et al., 1979). Affectively committed employees assimilate organisational beliefs into their own identity, which results in congruence of interests (Allen and Meyer, 1990). Moreover, their willingness to dedicate time, effort and talent to the organisation and their desire to belong to it and remain with it has positive implications for both individual and organisational performance (Organ and Paine, 2000; Parasuraman, 1987).

The adoption of an emotional labour strategy is reflected in a work experience. Several researchers have noted that work experiences are a crucial factor in affective commitment (e.g., Laschinger et al., 2001; Mathieu and Zajac, 1990; Meyer and Allen, 1991; Meyer et al., 1998; Steers, 1977). Factors associated with positive work experiences, such as performance feedback and a clear understanding of the role, have a positive impact on the development of affective commitment (Meyer et al., 2002). On the other hand, negative work experiences, such as a perceived discrepancy between the required emotions and those felt, and the effort required to present the required emotions, can help lessen affective commitment (Beck and Wilson,
2000). Furthermore, and depending on the emotional labour strategies adopted, the experiencing of positive emotions may generate positive feelings towards the work done and may also help increase affective commitment (Eby et al., 1999).

Thus, it seems likely that, in customer contacts, emotional labour strategies based on the authenticity of the emotional display, through deep acting or the expression of genuine emotions, may have a positive impact in affective commitment. It is to be expected, on the other hand, that strategies based on masking, through surface acting, will negatively influence affective commitment. Therefore, the following hypotheses are proposed:

H6a. Surface acting will be negatively related to affective commitment.

H6b. Deep acting will be positively related to affective commitment.

H6c. Expression of genuine emotions will be positively related to affective commitment.

Based on this literature review, an integrated model has been designed with the variables included in this study as well as the proposed hypotheses (Figure 1), where emotional labour strategies may arise as a function of the interaction between organisational and

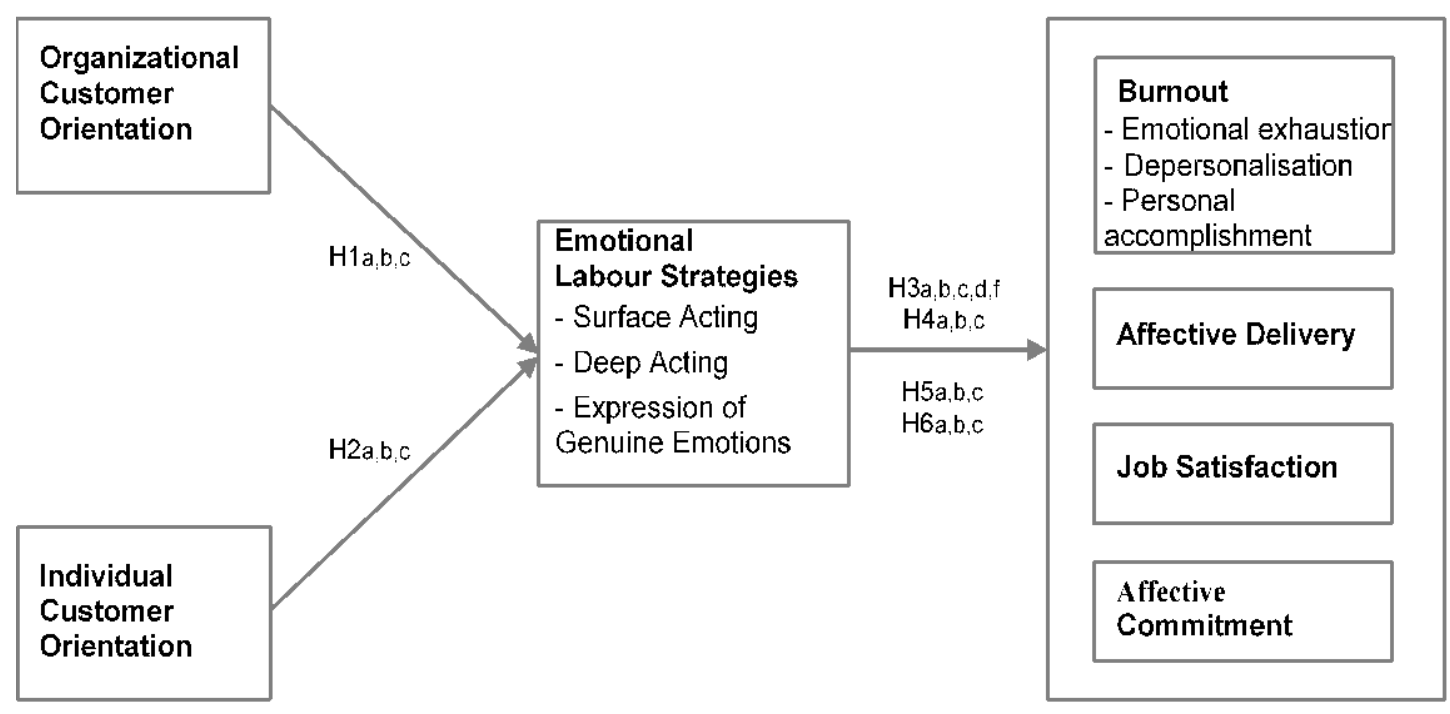

Figure 1. Research framework 
The influence of customer orientation on emotional labour and work outcomes: a study in the tourism industry.

individual customer orientation, which may have consequences for employee attitudes and work well-being.

\section{Research Method}

\section{Participants and Procedure}

Data were collected from a convenience sample of contact employees working in 43 hotels (all upscale establishments) and in 21 travel agencies, all located in Portugal. Initially, we contacted general managers and human resources directors inviting to participate and asking them to encourage the voluntarily participation of contact employees to complete a questionnaire. The questionnaire was accompanied by an explanatory note aiming to ensure the anonymity and confidentiality of the responses, and to make sure only the contact employees would complete the questionnaire. A total of 283 contact employees completed the questionnaire, out of which $39 \%$ were receptionists, $27 \%$ were waiters and $34 \%$ were travel agents. A total of $60 \%$ were female and $40 \%$ were male. Almost twenty-three per cent were younger than 30 years old, 35\% were between 30 and 39, 23\% were between 40 and 49 , and $19 \%$ were 50 or older. Thirty-two per cent of the participants had dropped out of school before the end of high school; 39\% completed high school; and $29 \%$ completed higher education. Twenty-five per cent had less than five years of organisational tenure; $13 \%$ between 5 and 8 years; and $62 \%$ more than 8 years. With regard to the continued employment and daily number of hours, $99.6 \%$ of employees work full time with a daily number of hours ranging from 8 to 9 hours (Table 1).

\section{Measures}

The dimensions for the proposed model were assessed by means of a questionnaire comprising 9 measures, all of them selfassessment scales, already applied in contact employees in previous studies, with a total of 71 items. All the measures had good internal consistency (Table 3), with $\alpha>0.70$, except for the measures for the expression of genuine emotions $(\alpha=0.69)$ and job satisfaction ( $\alpha$ $=0.67$ ) (Table 3). Participants rated each item using a 5-point Likert scale (5 = "strongly agree"; 1 = "strongly disagree") except for burnout ( 6 = "every day"; 0 = "never").

\section{Organisational customer orientation.}

Perceptions of the degree to which the organisation is customer-oriented were assessed with a nine-item scale developed by Deshpandé et al. (1993).

Individual customer orientation. The twelve items on the individual customer orientation scale were adopted from the SOcO Scale

Table 1. Sample characteristics

\begin{tabular}{llll}
\hline & & $\mathbf{N}$ & $\%$ \\
\hline Gender & Female & 169 & 59.7 \\
& Male & 114 & 40.3 \\
\hline Age & $<30$ Years old & 64 & 22.7 \\
& {$[30-39]$ Years old } & 100 & 35.3 \\
& {$[40-49]$ Years old } & 66 & 23.4 \\
& $\geq 50$ Years old & 53 & 18.6 \\
\hline Academic qualifications & Elementary education & 90 & 31.8 \\
& High school & 111 & 39.3 \\
& Higher education & 82 & 28.9 \\
\hline Frontline positions & Receptionists & 102 & 38.9 \\
& Waiters & 76 & 27.0 \\
& Travel agents & 97 & 34.1 \\
\hline Organisational tenure & Less than 5 years. & 71 & 25.1 \\
& {$[5-8]$ Years } & 36 & 12.7 \\
& More than 8 years & 176 & 62.2 \\
\hline Continued employment & Full time work & 282 & 99.6 \\
& Part-time work & 1 & 0.4 \\
\hline Daily number of hours & Less than 8 hours & 51 & 18.0 \\
& {$[8$ to 9] hours } & 184 & 64.9 \\
& More than 9 hours & 48 & 17.1 \\
\hline Total & & 283 & 100 \\
\hline
\end{tabular}


(Saxe and Weitz, 1982) and measure the degree to which the contact employee engages in customer-oriented service.

Emotional labour strategies. Items measuring surface acting, deep acting and expression of genuine emotions were adapted from Diefendorff et al. (2005). The seven items on the surface acting scale measure how much employees falsify emotions during their working day, in their interactions with customers. The four items on the deep acting scale measures the extent to which employees change the emotions they feel to display the required emotions. The three items on the expression of genuine emotions scale measure the extent to which employees express genuine emotions they feel.

Burnout. The three sub-scales of the burnout scale, namely emotional exhaustion, depersonalization, and personal accomplishment were adopted from The Maslach Burnout Inventory-Human Services Survey (Maslach, 1993). The nine items on the emotional exhaustion sub-scale measure emotional overload and the inability to respond to the interpersonal requirements of the work, because of the constant pressures involved. The five items on the depersonalization subscale measure the development of negative and insensitive attitudes towards people with whom the respondents interact at work. Finally, the eight personal accomplishment items measure the perception of job achievement, which results in such self-assessed feelings as success, high self-esteem and increased personal expectations. High scores on emotional exhaustion and depersonalization and low scores on personal accomplishment characterize burnout.

Affective delivery. Perceptions of affective delivery were adopted from Grandey (2003). The six items measure the extent to which interactions with customers are based on the expression of positive emotions.

Job satisfaction. Job satisfaction was assessed using the Michigan Organisational Assessment Questionnaire (Cammann et al., 1979), with three items, which measure overall job satisfaction.
Affective commitment. Affective commitment was assessed using a reduced version of the Mowday et al. (1979) scale, as also applied by Karatepe et al. (2007). This scale, with five items, measures the extent to which employees feel emotionally attached to the organisation.

\section{Data analysis}

Measurement properties and hypotheses were evaluated using Statistical Package for the Social Sciences (SPSS) (v.19) and Analysis of Moments Structures (AMOS) (v.19) software. In the first phase, it was assessed items' and dimensions' sensitivity by calculating the skewness and kurtosis indices to determine the normal distribution of the results. In the second phase, it was checked the internal structure of the measures using confirmatory factorial analysis (CFA). The Mahalanobis Distance ( $\left.{ }^{2}\right)$ statistic was used to identify any possible multivariate outliers. Whenever outliers were detected ( $p_{1}$ and $\left.p_{2}<0.05\right)$, CFA was applied. In the same way, the adjustment quality indices for the models were also assessed $(X 2 ; x 2 / d f$; CFI; GFI; PCFI; RMSEA; AIC; BCC and MECVI) - in those situations in which the model produced significant adjustment gains, the measurement errors were correlated. Once the overall adjustment quality of the model had been evaluated, local adjustment was determined. The items were checked for significant factorial weights $(\lambda \geq 0.5)$ and, consequently, an appropriate explained variance $\left(R^{2} \geq 0.5\right)$. The internal structure was only checked with respect to those measures that had initially presented a number above 3 items, thus assuring the presence of multiple indicators in the application of latent variables. For those measures for which this premise did not hold true, metric qualities were only applied to the item and respective dimension sensitivity assessment (see Table 2). In the third phase, Cronbach's Alpha indicator was used to evaluate the reliability of the measures.

\section{Results}

Correlation analysis

Correlation analysis (see Table 3 ) reveals that organisational customer orientation only has a significant positive association with the expression of genuine emotions $(r=0.24$, $p<0.01)$ whilst individual customer orientation correlates positively with deep acting $(r=0.13$, 
The influence of customer orientation on emotional labour and work outcomes: a study in the tourism industry.

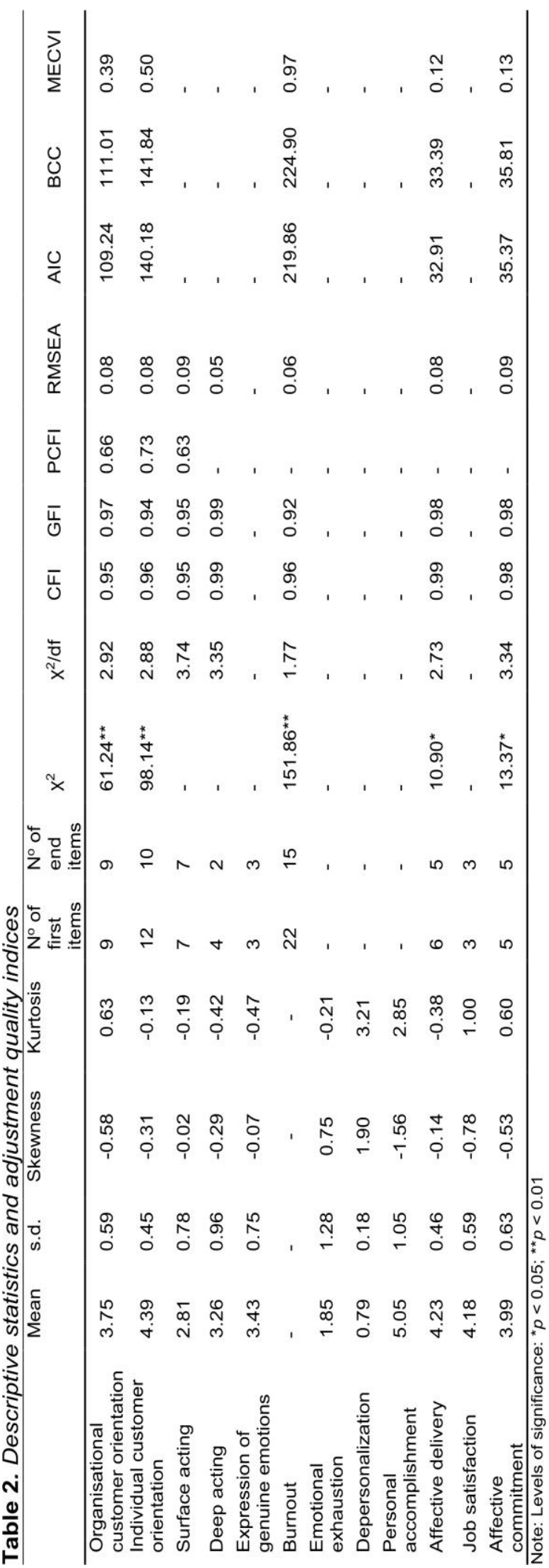

$p<0.05)$ and with the expression of genuine emotions $(r=0.18, p<0.01)$. It was confirmed that surface acting does not correlate with either of the two levels of customer orientation. The indices for the correlation of emotional labour strategies with outcomes show, as expected, that surface acting correlates positively with emotional exhaustion $(r=0.18$, $p<0.01)$ and with depersonalization $(r=0.23$, $p<0.01$ ). As predicted, surface acting correlates negatively with affective delivery $(r=-0.15$, $p<0.05)$ and with job satisfaction $(r=-0.15$, $p<0.05$ ). Deep acting only correlates positively with emotional exhaustion $(r=0.14, p<0.05)$. In terms of its association with other outcomes, it only correlates positively with affective commitment $(r=0.15, p<0.01)$. The data show that the expression of genuine emotions correlates positively with personal accomplishment $(r=0.19, p<0.01)$. It also correlates, in the expected directions, with affective delivery $(r=0.32, \quad p<0.01)$, job satisfaction $(r=0.17, p<0.01)$ and affective commitment $(r=0.15, p<0.05)$.

\section{Verification of research hypotheses}

The hypotheses were checked using structural equation models that drew on multiple linear regression and path analysis models. Given the high level of internal consistency of the dimensions in question, it was opted to analyse the models below using the path analysis method rather than use the corresponding latent variable models.

Correlation analysis showed that surface acting does not correlate with either of the two levels of customer orientation, so it was not included in the analysis. Table 4 shows that organisational customer orientation has a significant positive effect on the expression of genuine emotions $(\beta=0.20 ; \quad p<0.001)$, thus partially confirming hypothesis $H 1 b$. Individual customer orientation has a significant positive effect on deep acting $(\beta=0.13 ; p<0.0025)$ and on the expression of genuine emotions $(\beta=$ $0.11 ; p<0.050$ ), thus confirming hypothesis H2b.

In the case of hypotheses $H 3 a, b, c, d, f$, it was found that surface acting has a significant and positive impact on emotional exhaustion $(\beta=0.14 ; p=0.023)$ and on depersonalization 
Table 3. Reliabilities and correlations

\begin{tabular}{|c|c|c|c|c|c|c|c|c|c|c|c|c|}
\hline & Measures & $\alpha$ & 1 & 2 & 3 & 4 & 5 & 6 & 7 & 8 & 9 & 10 \\
\hline 1 & $\begin{array}{l}\text { Organisational Customer } \\
\text { Orientation }\end{array}$ & 0.85 & - & & & & & & & & & \\
\hline 2 & $\begin{array}{l}\text { Individual Customer } \\
\text { Orientation }\end{array}$ & 0.91 & $0.31^{*}$ & - & & & & & & & & \\
\hline 3 & Surface Acting & 0.85 & -0.08 & -0.01 & - & & & & & & & \\
\hline 4 & Deep Acting & 0.81 & 0.04 & $0.13^{*}$ & $0.42^{* *}$ & - & & & & & & \\
\hline 5 & $\begin{array}{l}\text { Expression of Genuine } \\
\text { Emotions }\end{array}$ & 0.69 & $0.24^{*}$ & $0.18^{* \prime}$ & $-0.52^{* *}$ & $-0.15^{*}$ & - & & & & & \\
\hline 6 & Emotional Exhaustion & 0.86 & $-0.16^{* \prime}$ & -0.08 & $0.18^{* *}$ & $0.14^{*}$ & -0.03 & - & & & & \\
\hline 7 & Depersonalization & 0.75 & $-0.12^{*}$ & -0.10 & $0.23^{* *}$ & 0.07 & -0.02 & $0.49^{* *}$ & - & & & \\
\hline 8 & $\begin{array}{l}\text { Personal } \\
\text { Accomplishment }\end{array}$ & 0.80 & $0.21^{*}$ & $0.34^{*}$ & -0.10 & 0.06 & $0.19^{*}$ & -0.11 & $-0.12^{\circ}$ & - & & \\
\hline 9 & Affective Delivery & 0.83 & $0.29^{*}$ & $0.60^{*}$ & $-0.15^{*}$ & 0.04 & $0.32^{*}$ & -0.11 & $-0.12^{\circ}$ & $0.29^{* *}$ & - & \\
\hline 10 & Job Satisfaction & 0.67 & $0.34^{* *}$ & $0.20^{*}$ & $-0.15^{*}$ & -0.07 & $0.17^{*}$ & $-0.39^{* *}$ & $-0.30^{* *}$ & $0.30^{* *}$ & $0.25^{*}$ & - \\
\hline 11 & Affective Commitment & 0.82 & $0.58^{* \prime}$ & $0.31^{*}$ & -0.03 & $0.15^{*}$ & $0.15^{*}$ & $-0.25^{* *}$ & $-0.16^{* *}$ & $0.29^{* *}$ & $0.33^{* *}$ & $0.48^{*}$ \\
\hline
\end{tabular}

Note: Levels of significance ${ }^{\star} p<0.05,{ }^{* \star} p<0.01$

Table 4. Multiple linear regression model between customer orientation and both deep acting and the expression of genuine emotions

\begin{tabular}{|c|c|c|c|c|c|c|c|c|}
\hline & \multicolumn{4}{|c|}{ Deep Acting } & \multicolumn{4}{|c|}{ Expression of Genuine Emotions } \\
\hline & $b$ & $\beta$ & $\mathrm{SE}_{b}$ & Z & $b$ & $\beta$ & $\mathrm{SE}_{\mathrm{b}}$ & $Z$ \\
\hline $\begin{array}{l}\text { Organisational } \\
\text { Customer Orientation }\end{array}$ & - & - & - & - & 0.263 & $0.203^{* *}$ & 0.077 & 3.423 \\
\hline $\begin{array}{l}\text { Individual Customer } \\
\text { Orientation }\end{array}$ & 0.281 & $0.132^{*}$ & 0.125 & 2.243 & 0.187 & $0.114^{*}$ & 0.098 & 1.895 \\
\hline
\end{tabular}

Note: Levels of significance: ${ }^{*} p<0.05 ;{ }^{* *} p<0.001$

Table 5. Multiple linear regression model between emotional labour strategies and the burnout dimensions emotional exhaustion, depersonalisation and personal accomplishment with standardized estimates

\begin{tabular}{|c|c|c|c|c|c|c|c|c|c|c|c|c|}
\hline & \multicolumn{4}{|c|}{ Emotional Exhaustion } & \multicolumn{4}{|c|}{ Depersonalisation } & \multicolumn{4}{|c|}{ Personal Accomplishment } \\
\hline & $b$ & $\beta$ & SEb & $Z$ & $b$ & $\beta$ & SEb & $Z$ & $b$ & $\beta$ & SEb & Z \\
\hline $\begin{array}{l}\text { Surface } \\
\text { Acting }\end{array}$ & 0.243 & $0.142^{*}$ & 0.107 & 2.269 & 0.357 & $0.227^{\star \star}$ & 0.091 & 3.931 & & & & \\
\hline $\begin{array}{l}\text { Deep } \\
\text { Acting } \\
\text { Expression }\end{array}$ & 0.123 & 0.091 & 0.076 & 1.620 & - & - & - & - & & & & \\
\hline $\begin{array}{l}\text { of Genuine } \\
\text { Emotions }\end{array}$ & - & - & - & - & - & - & - & - & 0.292 & $0.204^{\star *}$ & 0.083 & 3.528 \\
\hline
\end{tabular}

( $\beta=0.23 ; p<0.001)$, thus confirming hypothesis H3a. No firm relationship with personal accomplishment was found, thus hypothesis $\mathrm{H} 3 \mathrm{~b}$ is disproved. Deep acting is not a significant predictor in the model, and there is no significant alignment with emotional exhaustion $(\beta=0.09 ; \quad p=0.105)$, which means hypotheses $H 3 c$ and $H 3 d$ are refuted. The expression of genuine emotions only has a significant impact on personal accomplishment $(\beta=0.20 ; p<0.001)$, which bears out hypothesis H3f (see Table 5).

Results for Hypotheses $H 4 a, b, c ; H 5 a, b, c$ and $H 6 a, b, c$ shows that the expression of genuine emotions has a significant and positive impact on affective delivery $(\beta=0.33 ; \quad p<0.001)$, job satisfaction $(\beta=0.13 ; \quad p<0.050)$ and affective 
The influence of customer orientation on emotional labour and work outcomes: a study in the tourism industry.

Table 6. Multiple linear regression model between emotional labour strategies and affective delivery, job satisfaction and affective commitment

\begin{tabular}{|c|c|c|c|c|c|c|c|c|c|c|c|c|}
\hline & \multicolumn{4}{|c|}{ Affective delivery } & \multicolumn{4}{|c|}{ Job satisfaction } & \multicolumn{4}{|c|}{ Affective commitment } \\
\hline & $b$ & $\beta$ & SEb & Z & $b$ & $\beta$ & SEb & Z & b & $\beta$ & $\mathrm{SEb}_{b}$ & Z \\
\hline $\begin{array}{l}\text { Deep } \\
\text { Acting }\end{array}$ & - & - & - & - & - & - & - & - & 0.116 & $0.180^{*}$ & 0.038 & 3.074 \\
\hline $\begin{array}{l}\text { Expression } \\
\text { of Genuine } \\
\text { Emotions }\end{array}$ & 0.204 & $0.332^{\star *}$ & 0.041 & 5.015 & 0.102 & $0.128^{*}$ & 0.055 & 1.871 & 0.146 & $0.175^{*}$ & 0.049 & 2.988 \\
\hline
\end{tabular}

Note: Levels of significance: ${ }^{*} p<0.05 ;{ }^{* \star} p<0.001$

commitment $\quad(\beta=0.18 ; \quad p=0.003)$. Thus, hypotheses $H 4 c, H 5 c$ and $H 6 c$ are confirmed. Deep acting significantly and positively increases affective commitment $\quad(\beta=0.18$; $p=0.002$ ), thus substantiating hypothesis $\mathrm{H} 6 \mathrm{~b}$ (see Table 6).

\section{Discussion}

The primary objective of this study was to analyse the direct relationship of two levels of customer orientation, organisational and individual, in emotional labour strategies.

At the organisational level, the positive influence of customer orientation on the expression of genuine emotions evidences the increase of this dimension in the authentic display of appropriate emotions that do not need to be masked or emotionally regulated. The non-significant relationship with deep and surface acting strategies underlines the role played by $\mathrm{OCO}$ in reducing emotional discrepancy and the relevance this has for reducing the negative effects of emotional labour. These results are borne out by the marketing literature, which emphasizes the contribution OCO makes to ensure members of the organisation identifying themselves with their assigned roles, through an ongoing process of socialisation (Deshpandé et al., 1993; Narver and Slater, 1990). The identification with the organisational objectives and, consequently, with the required emotional labour promotes a natural alignment between what employees emotionally feel and what they express (Ashforth and Humphrey, 1993; Schaubroeck and Jones, 2000). The results can also be explained by OCO's contribution to the development of positive attitudes towards the client that will facilitate the experience of positive emotions during customer service
(Karatepe et al., 2007; Mengüc, 1996; Yoo and Arnold, 2014; Zablah et al., 2012) that will be reflected in an authentic emotional expression and facilitate the expression of genuine emotions (Brief and Weiss, 2002; Fisher, 2000; Motowidlo, 1984; Pugh, 2001; Tsai and Huang, 2002; Van Maanen and Kunda, 1989).

At the individual level, the positive relationship between customer orientation and both deep acting and the expression of genuine emotions reveals the advantage of this dimension in any selection of emotional labour strategies that are manifested in the authenticity of the emotional display, with or without emotional regulation. The result concurs with the literature, which establishes that customer-oriented employees invest time and effort in cooperating with customers to provide a reliable and authentic service (Brady and Cronin, 2001; Brotheridge and Grandey, 2002; Smith et al., 2012). In fact, the positive relationship between ICO and deep acting reveals this effort when the emotions felt are other than those required (Brown et al., 2002; Lee et al., 2016; Rupp et al., 2008; Zablah et al., 2012), a situation that allows them to have a positive relationship with the feeling of authenticity itself (Brotheridge and Lee, 2002). A study by Yoo and Arnold (2014) showed a positive relationship between ICO and the energy, dedication and involvement put into the customer service through the application of the deep acting strategy. The positive influence that ICO has on the expression of genuine emotions is endorsed by the literature, which describes customeroriented employees as developing positive attitudes towards customers (Saxe and Weitz, 1982) and as experiencing positive emotions during interactions (Donavan et al., 2004; Franke and Park, 2006; Harris et al., 2005; 
Keillor et al., 1999; Lee, Ok and Hwang, 2016; Zablah et al., 2012), both of which allow them to express their genuine emotions.

The second objective of this study was to test the influence of emotional labour strategies on four outcomes: burnout, affective delivery, job satisfaction and affective commitment.

The positive influence of surface acting on emotional exhaustion and depersonalization has also been shown in several empirical studies demonstrating the effects of maintaining a falsified expression, namely the impairment of self-image and the physical and psychological energy that has to be expended (Brotheridge and Grandey, 2002; Brotheridge and Lee, 2002; Hülsheger and Schewe, 2011; Kammeyer-Mueller et al., 2013; Lee and Woo, 2017; Lee et al., 2015). The emotional dissonance associated with surface acting has been identified as one of the dimensions responsible for both emotional exhaustion and depersonalization (e.g., Zapf, 2002; Zapf and Holz, 2006; Zapf et al., 2001). The study carried out by Brotheridge and Lee (2002) confirmed the idea that the "masking" of emotions weakens the sense of authenticity itself, which has repercussions for emotional exhaustion and for the development of insensitivity attitudes towards customers. The non-significant relationship between deep acting and the three dimensions of burnout is consistent with the results of previous studies (Brotheridge and Grandey, 2002; Brotheridge and Lee, 2002; Grandey, 2003; Lee and Woo, 2017). One potential explanation for this is the fact that deep acting can engender feelings of authenticity and also credible and gratifying emotional displays. This makes it possible to offset the negative effects that the effort of emotional regulation has on an employee's physical and psychological well-being (Barger and Grandey, 2006; Brotheridge and Lee, 2002; Gosserand and Diefendorff, 2005; Grandey, 2000, 2003; Grandey et al., 2005; Sheldon et al., 1997). Lastly, the relationship between the strategy of expressing genuine emotions and personal accomplishment, on its own, shows that the absence of emotional regulation does not establish a relationship with the physical or psychological strain felt by employees. This is consistent with the findings of the study carried out by Brotheridge and Lee
(2002), which showed the influence that the sense of authenticity has over the degree of personal accomplishment felt by employees.

About the effect of emotional labour strategies on affective delivery, it was only found a positive significant relationship for the expression of genuine emotions in this dimension. It was assumed that forms of emotional presentation, based on the authenticity of the emotional display, facilitate the efficacy of the performance. More specifically, Grandey (2003) found a positive relationship between deep acting and affective delivery and a negative relationship between surface acting and this same dimension. Despite the fact that results do not support this assumption, they are consistent with the study of Gosserand and Diefendorff (2005), who, using the same measure as Grandey (2003) and as the one used in this study, found a nonsignificant relationship with deep acting. It should be noted that these studies only looked at the two emotional acting strategies (deep acting and surface acting) and not at the expression of genuine emotions. Although this fact makes any comparative analysis more difficult, it also allows for the possibility that the expression of genuine emotions can constitute a relevant form of emotional presentation for the purposes of delivering affective delivery.

The observation of the effect of emotional labour strategies on job satisfaction resulted in only one positive significant relationship for the expression of genuine emotions in this dimension. While earlier studies have shown the role of deep acting in the production of lower levels of negative emotions and greater job satisfaction (Brotheridge and Lee, 2002; Grandey, 2003; Groth et al., 2009; Hülsheger and Schewe, 2011; Lee and Woo, 2017), the exclusive relationship of the expression of genuine emotions in job satisfaction can be explained by the natural experiencing of positive emotions that may trigger positive work experiences and, consequently, enhance job satisfaction (Fisher, 2000; Hsieha, 2016). According to Adelmann (1995), employees who express themselves genuinely are more satisfied at work than those who falsify the emotions they present. Additionally, and from the point of view of emotional display, the 
The influence of customer orientation on emotional labour and work outcomes: a study in the tourism industry.

results obtained agree with the literature where this emphasizes the positive relationship between the authenticity of the emotional display and job satisfaction (Sheldon et al., 1997).

Finally, the influence of both deep acting and the expression of genuine emotions on affective commitment reflects employee alignment with the organisation's target emotions, whether this is natural or forced. The veracity of the emotional display may engender positive relationships with the customers and positive work experiences that, according to the literature, benefit affective commitment (Beck and Wilson, 2000; Meyer, 2002). Similarly, the experiencing of positive emotions in customer contact situations will produce positive feelings about the work that can feed the affective commitment (Eby et al., 1999).

\section{Conclusions, limitations and further research}

The inclusion of variables pertaining to customer worth at both the organisational (OCO) and individual (ICO) levels broadened the possibilities about what could influence emotional labour strategies and the advantages these enjoy in the production of authentic displays in customer service situations.

The evaluation of the expression of genuine emotions, along with the strategies most often referred to in the specialist literature (surface and deep acting), has contributed to a fuller understanding of emotional labour strategies. It has also consolidated the relevance of these strategies, both as a consequence of customer orientation and as a predictor of a set of outcomes of interest to the tourism industry. It was observed that the expression of genuine emotions occupies a prominent place in the presentation of appropriate emotions, in agreement with the literature which has pointed out the usefulness of this dimension as an emotional labour strategy.

This study confirms the results of earlier researchers by showing that the "masking" of emotions leads to psychological and physical exhaustion and negative and insensitive attitudes towards customers. The inclusion of the expression of genuine emotions underscores the importance of this dimension to self-esteem, to positive feelings about the work and to employee identification with the organisation, particularly about their contribution to the delivery of affective and authentic customer service provision.

To ensure the well-being of the workers, it would be useful to have the skills to better manage their emotions and their relationship with customers. Managing emotions well through expression of genuine emotions can have a positive impact on employees, as demonstrated in this study (decreased burnout and increased affective delivery, job satisfaction and commitment), that may have repercussions on customer satisfaction and perceptions of quality of services.

Findings should be interpreted in the light of a set of limitations that will, however, leverage further research. For example, the inclusion of organisational and individual customer orientation has somewhat hampered the theoretical underpinning of the results obtained, given that there are, as yet, very few studies that relate these issues with emotional labour strategies. It is therefore recommended that further research that tests the predictor value of these dimensions and analyses other influencing factors, such as variables that mediate or moderate this relationship, particularly commitment to the rules of emotional presentation and the support received from managers and colleagues. This study makes use of self-report data, so future studies with multiple methods would be useful. It will be important to have objective measure for customer-oriented behaviours (e.g. periodic performance appraisals).

Further, the data of the study is cross-sectional, and the conducted analyses were correlational, so causal conclusions cannot be consistently drawn. Studies using a longitudinal design would be important to confirm the effects raised in this study, how behaviour experiences in customer contact work, and well-being change during a period of time would be interesting.

\section{References}

Adelmann, P.K. (1995). Emotional labor as a potential source of job stress. In S.L. 
Sauter \& L.R. Murphy (Eds.), Organizational risk factors for job stress, Washington, DC: American Psychological Association, 371-381.

Allen, N.J., \& Meyer, J.P. (1990). The measurement and antecedents of affective, continuance and normative commitment to the organization. Journal of Occupational Psychology, 63 (1), 1-18.

Ashforth, B.E., \& Humphrey, R.H. (1993). Emotional labor in service roles: The influence of identity. Academy of Management Review, 18 (1), 88-115.

Barger, P.B., \& Grandey, A.A. (2006). Service with a smile and encounter satisfaction: emotional contagion and appraisal mechanisms. Academy of Management Journal. 49 (6), 1229-1238.

Beck, K., \& Wilson, C. (2000). Development of affective organizational commitment: across-sequential examination of change with tenure. Journal of Vocational Behavior, 56, 114-136.

Bettencourt, L.A., Gwinner, K.P., \& Meuter, M.L. (2001). A comparison of attitude, personality, and knowledge predictors of service-oriented organizational citizenship behaviors. Journal of Applied Psychology, 86 (1), 29-41.

Brady, M.K., \& Cronin, J. J. Jr. (2001). Customer orientation: effects on customer service perceptions and outcome behaviours. Journal of Service Research, 3 (3), 241-251.

Brief, A.P., \& Weiss, H.M. (2002). Organizational behaviour: affect in the workplace. Annual Review of Psychology, 53 (1), 279-307.

Brotheridge, C.M., \& Grandey, A.A. (2002). Emotional labor and burnout: Comparing two perspectives of people work. Journal of Vocational Behavior, 60, 17-39.

Brotheridge, C.M., \& Lee, R.T. (2002). Testing a conservation of resources model of the dynamics of emotional labor. Journal of Occupational Health Psychology, 7 (1), 57-67.

Brown, T.J., Mowen, J.C., Donavan, D.T., \& Licata, J.W. (2002). The customer orientation of service workers: personality trait effects on self - and supervisor performance ratings. Journal of Marketing Research, 39, 110-119.
Cammann, C., Fichman, M., Jenkins, D., \& Klesh, J. (1979). The Michigan organizational assessment questionnaire. Ann Arbor, MI, Unpublished manuscript.

Carr, J. C., \& Lopez, T. B. (2007). Market orientation as both culture and conduct: Modeling the relationships between market orientation and employee responses. Journal of Marketing Theory and Practice, 15 (2), 113-127.

Chung, B.G., \& Schneider, B. (2002). Serving multiple masters: Role conflict experienced by service employees. Journal of Services Marketing, 10 (1), 7087.

Deshpandé, R., Farley, J.U., \& Webster, F.E., Jr. (1993). Corporate culture, customer orientation, and innovativeness in Japanese firms: A quadrad analysis. Journal of Marketing, 57 (1), 23-37.

Diefendorff, J.M., Croyle, M.H., \& Gosserand, R.H. (2005). The dimensionality and antecedents of emotional labor strategies. Journal of Vocational Behavior, 66 (2), 339-357.

Diefendorff, J.M, Greguras, G.J. \& Fleenor, J. (2016). Perceived emotional demandsabilities fit. Applied Psychology, 65, 2-37.

Diefendorff, J.M., \& Gosserand, R.H. (2003). Understanding the emotional labor process: a control theory perspective. Journal of Organizational Behavior, 24 (8), 945-959.

Diefendorff, J.M., Erickson, R., Grandey, A., \& Dahling, J. (2011). Emotional display rules as work unit norms: a multilevel analysis of emotional labor among nurses. Journal of Occupational Health Psychology, 16 (2), 170-186.

Donavan, D.T., Brown, T.J., Mowen, J.C. (2004). Internal benefits of service-worker customer orientation: job satisfaction, commitment, and organizational citizenship behaviors. Journal of Marketing, 68, 128-146.

Eby, L.T., Freeman, D.M., Rush, M.C., \& Lance, C.E. (1999). Motivational bases of affective organizational commitment: a partial test of an integrative theoretical model. Journal of Occupational and Organizational Psychology, 72 (4), 463483. 
The influence of customer orientation on emotional labour and work outcomes: a study in the tourism industry.

Ekman, P., Friesen, W.V., \& O'Sullivan, M. (1988). Smiles when lying. Journal of Personality and Social Psychology, 54, 414-420.

Fisher, C.D. (2000). Moods and emotions while working: Missing pieces of job satisfaction? Journal of Organizational Behavior, 21 (2), 185-202.

Frank, M. G., Ekman, P., \& Friesen, W. V. (1993). Behavioral markers and recognizability of the smile of enjoyment. Journal of Personality and Social Psychology, 64 (1), 3-93.

Franke, G.R., \& Park, J.E. (2006). Salesperson adaptive selling behavior and customer orientation: a meta-analysis. Journal of Marketing Research, 43 (4), 693-702.

Gosserand, R.H., \& Diefendorff, J.M. (2005). Emotional display rules and emotional labor: The moderating role of commitment. Journal of Applied Psychology, 90 (6), 1256-1264.

Grandey, A. (2000). Emotional regulation in the workplace: A new way to conceptualize emotional labor. Journal of Occupational Health Psychology, 5 (1), 95-110.

Grandey, A. (2003). When "the show must go on: Surface acting and deep acting as determinants of emotional exhaustion and peer-rated service delivery. Academy of Management Journal, 46 (1), 86-96.

Grandey, (2015). Smiling for a wage: what emotional labor teaches us about emotion regulation. Psychological Inquiry, 26, 5460.

Grandey, A., \& Gabriel, A. (2015). Emotional labor at a crossroads: Where do we go from here? Annual Review of Organizational Psychology and Organizational Behavior, 2, 323-349.

Grandey, A., Fisk, G., Mattila, M., Jansen, K., \& Sideman, L. (2005). Is "service with a smile enough? Authenticity of positive displays during service encounters. Organizational Behavior and Human Decision Processes, 96, 38-55.

Grönroos, C. (2001). The perceived service quality concept - a mistake? Managing Service Quality, 11 (3), 150-151.

Groth, M., Hennig-Thurau, T., \& Walsh, G. (2009). Customer reactions to emotional labor: the roles of employee acting strategies and customer detection accuracy, Academy of Management Journal, 52 (5), 958-974.

Harris, E.G., Mowen, J.C., \& Brown, T.J. (2005). Reexamining salesperson goal orientations: personality influencers, customer orientation, and work satisfaction. Journal of the Academy of Marketing Science, 33 (1), 19-35.

Hsieha, C., Hsiehb, J., \& Huang, I.Y. (2016). Self-efficacy as a mediator and moderator between emotional labor and job satisfaction: A case study of public service employees in taiwan. Public Performance \& Management Review, 40, 71-96.

Hochschild, A. R. (1983). The managed heart: Commercialization of human feeling. Berkeley: University of California Press.

Homburg, C.W., \& Hoyer, W.D. (2009). Social Identity and the Service-Profit Chain. Journal of Marketing, 73 (2), 38-54.

Hülsheger, U.R., \& Schewe, A.F. (2011). On the costs and benefits of emotional labor: a meta-analysis of three decades of research. Journal of Occupational Health Psychology, 16 (3), 361-389.

Hur, W.M., Han, S., Yoo, J., \& Moon, T.W. (2015). The moderating role of perceived organizational support on the relationship between emotional labour and job-related outcomes. Management Decision, 53 (3), 605-624.

Judge, T.A., Woolf, E.F., \& Hurst, C. (2009). Is emotional labor more difficult for some than for others? A multilevel, experience sampling study. Personnel Psychology, 62 (1), 57-88.

Kammeyer-Mueller, J.D., Rubenstein, A.L., Long, D.M., Odio, M.A., Buckman, B.R., Zhang, Y., \& Halvorsen-Ganepola, M.D.K. (2013). A meta-analytic structural model of dispositional affectivity and emotional labor. Personnel Psychology, 66, 47-90.

Karatepe, O.M., \& Choubtarash, H. (2014). The effects of perceived crowding, emotional dissonance, and emotional exhaustion on critical job outcomes: a study of ground staff in the airline industry. Journal of Air Transport Management, 40, 182-191.

Karatepe, O.M., Yavas, U., \& Babakus, E. (2007). The effects of customer orientation and job resources on frontline employees' job outcomes. Services Marketing Quarterly, 29 (1), 61-79. 
Keillor, B.D., Parker, R.S., \& Pettijohn C.E. (1999). Sales force performance satisfaction and aspects of relational selling: implications for sales managers, Journal of Marketing Theory and Practice, 7 (1), 101-115.

Kim, H.J., Hur, W.M., Moonc, T.W., Jun, J.K. (2017). Is all support equal? The moderating effects of supervisor, coworker, and organizational support on the link between emotional labor and job performance. Business Research Quarterly, 20, 124-136.

Kohli, A.K., \& Jaworski, B.J. (1990). Market orientation: the construct, research propositions, and managerial implications. Journal of Marketing, 54 (2), 1-18.

Laschinger, H.K., Finegan, J., \& Shamian, J. (2001). The impact of workplace empowerment, organizational trust on staff nurse's work satisfaction and organizational commitment. Health Care Management Review, 26 (3), 7-23.

Lee, J., Ok, C., \& Hwang, J. (2016). An emotional labor perspective on the relationship between customer orientation and job satisfaction. International Journal of Hospitality Management, 54, 139-150.

Lee, Y.; Chelladurai, P., \& Kim, Y. (2015). Emotional labor in coaching: Development of a model. International Journal of Coaching and Sport Science, $10(2,3)$, $561-575$

Lee, Y., \& Woo, B. (2017). Emotional labour, emotional exhaustion, job satisfaction and organisational citizenship. behaviour among Korean fitness employees. South African Journal for Research in Sport, Physical Education and Recreation, 39 (2), 137-148.

Lepeley, M.T. (2017). Five Pillars of Quality Organizations and Global Sustainability" UK: Greenleaf Publishing.

Lings, I.N., \& Greenley, G.E. (2010). Internal market orientation and market-oriented behaviours. Journal of Service Management, 21 (3), 321-343.

Locke, E.A. (1976). The nature and causes of job satisfaction. In Dunnette, M.D. (ed.), Handbook of Industrial and Organizational Psychology, Rand-McNally, Chicago, IL, 1297-1349.
Maslach, C. (1993). Burnout: a multidimensional perspective. In Schaufeli, W.B., Maslach, C., \& Marek, T. (eds.), Professional Burnout: Recent Developments in Theory and Research, Taylor and Francis, Washington, DC, 1932.

Mathieu, J.E., \& Zajac, D. (1990). A review and meta-analysis of the antecedents, correlates and consequences of organizational commitment. Psychological Bulletin, 108 (2), 171-194.

Mengüc, B. (1996). The influence of the market orientation of the firm on sales force behavior and attitudes: further empirical results. International Journal of Research in Marketing, 13 (3), 277-291.

Meyer, J.P., \& Allen, N.J. (1991). A threecomponent conceptualization of organizational commitment. Human Resource Management Review, 1 (1), 6189.

Meyer, J.P., Irving, P.G., \& Allen, N.J. (1998). Examination of the combined effects of work values and early work experiences on organizational commitment. Journal of Organizational Behavior, 19 (1), 29-52.

Meyer, J., Stanley, D., Herscovich, L., \& Topolnytsky, L. (2002). Affective, continuance, and normative commitment to the organization: A meta-analysis of antecedents, correlates, and consequences. Journal of Vocational Behavior, 61 (1), 20-52.

Middleton, D.R. (1989). Emotional style: The cultural ordering of emotions. Ethos.17 (2), 187-201.

Morris, J.A., \& Feldman, D.C. (1996). The dimensions, antecedents, and consequences of emotional labor. Academy of Management Review, 21 (4), 986-1010.

Morris, J.A., \& Feldman, D.C. (1997). Managing emotions in the workplace. Journal of Managerial Issues, 9 (3), 257274.

Motowidlo, S.J. (1984). Does job satisfaction lead to consideration and personal sensitivity? Academy of Management Journal, 27 (4), 910-15.

Mowday, R.T., Steers, R.M., \& Porter, L.W. (1979). The measurement of 
The influence of customer orientation on emotional labour and work outcomes: a study in the tourism industry.

organizational commitment", Journal of Vocational Behavior, 14, 224-247.

Mróz, J. \& Kaleta, K. (2016). Relationships between personality, emotional labor, work engagement and job satisfaction in service professions. International Journal of Occupational Medicine and Environmental Health, 29 (5), 767-782.

Narver, J.C. \& Slater, S.F. (1990). The effect of a market orientation on business profitability. Journal of Marketing, 54 (4), 20-35.

Organ, D.W., \& Paine, J.B. (2000). Contingent and marginal employment, commitment, and discretionary contributions. In $\mathrm{R}$. Hodson (ed.), Research in the Sociology of Work, Stamford, CT: JAI Press, 253270.

Parasuraman, A. (1987). Customer-oriented corporate cultures are crucial to services marketing success. Journal of Services Marketing, 1 (1), 39-46.

Pelham, A. (2009). An exploratory study of the influence of firm market orientation on salesperson adaptive selling, customer orientation, interpersonal listening in personal selling and salesperson consulting behaviors. Journal of Strategic Marketing, 17 (1), 21-39.

Pugh, S. D. (2001). Service with a smile: Emotional contagion in the service encounter. Academy of Management Journal, 44 (5), 1018-1027.

Pugh, D., Groth, M., \& Hennig-Thurau, T. (2011). Willing and able to fake emotions: A closer examination of the link between emotional dissonance and employee wellbeing. Journal of Applied Psychology, 96 (2), 377-390.

Rafaeli, A., \& Sutton, R. I. (1987). The expression of emotion as part of the work role. Academy of Management Review, 12 (1), 23-37.

Rafaeli, A., \& Sutton, R. I. (1989). The expression of emotion in organizational life. Research in Organizational Behavior. 11 (1), 1-42.

Rogers, J.D., Clow, K.E., \& Kash, T.J. (1994). Increasing job satisfaction of service personnel. Journal of Services Marketing, 8 (1), 14-26.

Rupp, D.E., McCance, A.S., Spencer, S., \& Sonntag, K. (2008). Customer (in) justice and emotional labor: the role of perspective taking, anger, and emotional regulation. Journal of Management, 34, 903-924.

Saxe, R., \& Weitz, B.A. (1982). The SOCO scale: A measure of the customer orientation of salespeople. Journal of Marketing Research, 19 (3), 343-351.

Schaubroeck, J., \& Jones, J.R. (2000). Antecedents of workplace emotional labor dimensions and moderators of their effects on physical symptoms. Journal of Organizational Behavior, 21 (2), 163-183.

Schneider, B., \& Bowen, D. (1985). Employee and customer perceptions of service in banks: Replication and extension. Journal of Applied Psychology, 70 (3), 423-433.

Sheldon, K.M., Ryan, R.M., Rawsthorne, L.J., \& Hardi, B. (1997). Trait self and true self: Cross-role variation in the big-five personality traits and its relations with psychological authenticity and subjective well-being. Journal of Personality and Social Psychology, 73, 1380-1393.

Smith, M.R., Rasmussen, J.L., Mills, M.J., Wefald, A.J., \& Downey, R.G., (2012). Stress and performance: do service orientation and emotional energy moderate the relationship? Journal of Occupational Health Psychology, 17, 116128.

Steers, R.M. (1977). Antecedents and outcomes of organizational commitment. Administrative Science Quarterly, 22 (1), 46-56.

Tax, S.S., McCutcheon, D., \& Wilkinson, I.F. (2013). The service-delivery network (SDN): A customer-centric perspective of the journey. Journal of Service Research, 16 (4), 454-470.

Tsai, W.C., \& Huang, Y. (2002). Mechanisms linking employee affective delivery and customer behavioral intentions. Journal of Applied Psychology, 87 (5), 1001-1008.

Wang, X., Wang, G., \& Hou, W.C., (2016). Effects of emotional labor and adaptive selling behavior on job performance. Social Behavior and Personality, 44 (5), 801-814.

Van Maanen, J., \& Kunda, G. (1989). Real feelings: emotional expression and organizational culture. In Cummings, L., \& Staw, B. (eds). Research in 
Organizational Behavior, 11. Greenwich, CT: JAI Press, 43-103.

Yoo, J.J., \& Arnold, T.J. (2014). Customer orientation, engagement, and developing positive emotional labor. The Service Industries Journal, 34 (16), 1272-1288.

Zapf, D. (2002). Emotion work and psychological well-being: A review of the literature and some conceptual considerations. Human Resource Management Review, 12 (2), 237-268.

Zapf, D., \& Holz, M. (2006). On the positive and negative effects of emotion work in organizations. European Journal of Work and Organizational Psychology, 15 (1), 128.
Zapf, D., Seifert, C., Schmutte, B., Mertini, H., \& Holz, M. (2001). Emotion work and job stressors and their effects on burnout. Psychology and Health, 16 (5), 527-545.

Zablah, A.R., Franke, G.R., Brown, T.J., \& Bartholomew, D.E. (2012). How and when does customer orientation influence frontline employee job outcomes? A metaanalytic evaluation. Journal of Marketing, 76 (3), 21-40.

Zeithaml, V.A., \& Gremler, D.D. (2017). Services marketing: Integrating customer focus across the firm (7th ed.). McGrawHill, NY. 